\title{
Survey of disability, accessibility and utilization of rehabilitation service, in a community of Kano State: North Western Nigeria
}

\begin{abstract}
Objective: Disability is both a cause and a consequence of poverty, reducing access to education, employment, opportunities and resources. Poor people without disabilities can develop them, due to inadequate nutrition, unclean environments, disease, insufficient health services and poor infrastructure. The purpose of this study was to determine the level of disability, accessibility and utilization of rehabilitation service, in gwan-gwan community.
\end{abstract}

Method: Eighty six (86) people participated in the study, the participants were choosen using multistage sampling technique, questionnaire was administered to the subjects, information about disability, type of disability, access and utilization of rehabilitation services was collected and analysed descriptively.

Result: Findings of the study showed that majority of the participants are disabled (55.7\%), back has the highest form of disability (26.1\%), they don't have access to rehabilitation centres $(63.6 \%)$ and also they don't utilize rehabilitation service $(78.4 \%)$.

Conclusion: It was therefore concluded that majority of people of this community are living with disability with lack of accessibility to rehabilitation centers and less utilisation of rehabilitation services. It is therefore, recommended that government of Nigeria should lead the way in making accessibility of rehabilitation centres a priority. This can be achieved by enacting laws which protect the accessibility rights of people living with disability.

Keywords: disability, accessibility, utilization, rehabilitation service
Volume 3 Issue 5 - 2018

Farida Garba Sumaila, Hadiza Abdullahi, Aishat Shittu

Department of Physiotherapy, Faculty of Allied Health Sciences, Bayero University Kano, Nigeria

\begin{abstract}
Correspondence: Farida Garba Sumaila, Department of Physiotherapy, Faculty of Allied Health Sciences, College of Health Sciences, Bayero University Kano, Nigeria, Tel +234 803 6164228,07085769215, Email farendat2006@gmail.com, fgsumayla.pth@buk.edu.ng
\end{abstract}

Received: January 08, 2018 | Published: October 29, 2018

\section{Introduction}

Disability is both a cause and a consequence of poverty, ${ }^{1}$ reducing access to education, employment, opportunities and resources. Poor people without disabilities can develop them, due to inadequate nutrition, unclean environments, disease, inefficient health services and poor infrastructure. ${ }^{2}$ Untreated and chronic diseases affect increasing numbers of people in developing countries, resulting in physical and functional disability. ${ }^{3}$

Preventable disease, congenital malformation, birth related incidents, physical injury and psychological dysfunction all produce disability. Most neonatal deaths in developing countries result from infections, pre-term delivery and asphyxia, and disabilities for survivors can include cerebral palsy, spina bifida, congenital deformities and encephalitis. ${ }^{4,5}$ At least six preventable diseases of childhood - measles, poliomyelitis, diphtheria, tetanus, tuberculosis and whooping cough - can cause visual, auditory, physical and intellectual disability. ${ }^{6,7}$

An estimated $10 \%$ of any population is likely to be disabled, and up to one in five of the world's poorest have a disability. ${ }^{8}$ With a population of over 140 million, Nigeria has approximately 14 million people with disabilities. ${ }^{9}$

Two thirds of the world's 278 million individuals with hearing impairments live in developing countries, where the prevalence rates for bilateral hearing impairment at birth range from 2-4 per 1,000 live births. ${ }^{10}$ In sub-Saharan Africa, which includes Nigeria, higher rates of diseases that may affect hearing (eg. malnutrition, chronic otitis media, and meningitis) exist ${ }^{11}$ and access to immunisation against measles, mumps and rubella - causes of childhood deafness - is impeded by poverty. Deaf people tend to be marginalised, live in isolation, and cannot hear public health messages. ${ }^{12}$

In Nigeria, mental illness is highly stigmatised and symptoms are hidden or denied. Nigeria has fewer than 100 psychiatrists for its population and less than $1 \%$ of sufferers have access to psychiatric support or treatment. ${ }^{13}$ A recent national survey of 5,000 randomly selected participants, found $23 \%$ had experienced a psychiatric episode but only $8 \%$ received any treatment. ${ }^{13}$

Disability is both a cause and a consequence of poverty. There is a strong relationship between disability and poverty with a cyclical tendency - poverty makes people more vulnerable to disability and disability reinforces and deepens poverty. Disability is an important factor, along with gender, race and caste, that interacts to impoverish people and keep them poor. ${ }^{14}$ People with disability are often excluded from the mainstream of society, and hence, may not contribute to the development of the society at all or optimally. It is increasingly being recognized that bringing people with disabilities into the development mainstream will have a significant effect in any plan to cut poverty in the developing world. This is especially true, given that disability affects not only the individual, but also the family and society. In Africa, previous efforts to put disability in the fore front of the 
development agenda has not yielded all the expected results. This was as a result of poor resources, blamed partly on the lack of commitment on the part of governments. ${ }^{15}$

Accessibility is an important consideration for healthcare providers as delay in receiving care may lead to increased chronicity of new conditions, seriousness of symptoms and an overall reduction in health status. Furthermore, facilities which provide good access are likely to have high levels of patient satisfaction in terms of the provision of care. ${ }^{16}$

Accessibility of services is essential if the goal of fostering functional independence is to be achieved in people with disability. Accessibility to rehabilitation services is currently very poor in many developing countries. ${ }^{16}$ This shows the importance the society attaches to people with disability. Rehabilitation is usually considered as a sort of optional extra to the more 'important' medical care. ${ }^{17}$ The fact that it is through rehabilitation that functional independence is restored, makes it liberating to people with disability and indeed important to the society that cares to have a productive citizenry. Many of the people with disability do not have the funds to pay for rehabilitation services, In addition, therapists are not available in enough numbers and geographical spread to provide the required access throughout the country. ${ }^{17}$

The restoration of a client to his/her former environment and lifestyle is one of the most important objectives of rehabilitation. ${ }^{18-20}$ Rehabilitation also allows an individual to achieve satisfaction in productive activity and personal fulfilment by participating in social and functional interaction with other people. ${ }^{21}$ The most likely common handicap among people living with Disability is restriction of mobility. ${ }^{22}$

For some people with disabilities, rehabilitation is essential to participate in education, the labour market and civic life. Rehabilitation is always voluntary, and some individuals may require support with decision making about rehabilitation choices, Rehabilitation that begins early produces better functional outcomes for almost all health conditions associated with disability ${ }^{23}$ and has proven to increase educational and developmental gains to a person achieving and maintaining optimal function in interaction with there environment, using the following broad outcomes: Prevention of the loss of function, Slowing the rate of loss of function, Improvement or restoration of function, Compensation for loss function, Maintenance of current function. ${ }^{23}$

National studies on living conditions of people with disability conducted in Malawi, Mozambique, Namibia, Zambia and Zimbabwe ${ }^{24}$ revealed large gaps in the provision of medical rehabilitation and assistive devices. Gender inequalities in access to assistive devices were evidence in Malawi (Men 25.3\% and Women 14.1\%) and Zambia (Men 15.7\% and Women 11.9\%). ${ }^{24}$

A survey of physical rehabilitation medicine in croatia, the Czech republic, hungary, Slovakia, and Slovenia, found a general lack of access to rehabilitation in primary, secondary, tertiary, and community health care settings, as well as regional and socioeconomic inequalities in access. ${ }^{24}$

In a study of people identified as disabled from three districts in Beijing, china, $75 \%$ of those interviewed expressed a need for a range of rehabilitation services, of which only $27 \%$ had received such services. ${ }^{25}$ A national Chinese study of the need for rehabilitation in 2007 found that unmet need was particularly high for assistive devices and therapy. ${ }^{26}$
Therefore the study tends to determine the prevalence of disability, accessibility and utilization of rehabilitation services in gwan-gwan community of Kano North western part of Nigeria.

\section{Methodology}

\section{Research design}

The study was a descriptive survey to determine prevalence of disability, accessibility and utilization of rehabilitation services among disabled and non disabled in gwan-gwan community.

\section{Population of the study}

The population for this study was sampled out from people leaving in gwan-gwan community, Kano state.

\section{Sample size and sampling technique}

A total of 86 subjects were sampled out, using multistage sampling technique. The following method was used in sampling out the subject.

From a total of 5 polling units in the community, 3 houses were selected from each unit and total of 15 houses were sampled out. All adult individuals in the 15 houses were involved in the study.

\section{Data collection instrument}

1. Disability survey questionnaire.

2. Consent form.

\section{Data collection procedure}

An introduction letter from the department was presented to the district head of gwan-gwan community. Each participant was required to sign a consent form, agreeing to participate in the study. The aims of the research and the importance of the outcomes was explained to the participants, the participants were given some time to think, The respondents were assured of the confidentiality of their responses. Questions were asked to each of the participants and the responses will be recorded or ticked in the appropriate boxes.

\section{Data analysis procedure}

Data obtained was analyzed using statistical package for the social sciences (SPSS), and the results was presented using descriptive statistics.

\section{Results}

A total of 86 people participate in the study. Table 1 shows that more than half of the participants (55.7\%) have disability. Table 2 shows that percentage of participants with back Disability is higher than other types of disability with about $26.1 \%$, Polio and VIC constitute the lowest percentage of $1.1 \%$ each. Table 3 shows that Majority of the participants doesn't have knowledge and accessibility about rehabilitation centre, constitute about $63.6 \%$. Table 4 shows that $19.3 \%$ visit rehab center while $78.4 \%$ does not utilize rehabilitation service.

Table I Disability

\begin{tabular}{lll}
\hline Variables & Frequency & Percentage\% \\
\hline Disability & & \\
Yes & 49 & $55.70 \%$ \\
No & 37 & $42 \%$ \\
\hline
\end{tabular}


Table 2 Types of disability sustained by respondants

\begin{tabular}{lll}
\hline Type of disability & Frequency & Percentage \\
\hline Knee & 17 & $19.30 \%$ \\
Back & 23 & $26.10 \%$ \\
Paralysis & 5 & $5.70 \%$ \\
Cerebral palsy & 2 & $2.30 \%$ \\
Polio & 1 & $1.10 \%$ \\
V.I.C & 1 & $1.10 \%$ \\
\hline
\end{tabular}

Table 3 Accessibility to rehabilitation centre

\begin{tabular}{lll}
\hline Variables & Frequency & Percentage \\
\hline Knowledge about rehab centre & 30 & \\
Yes & 50 & $34.10 \%$ \\
No & & $63.60 \%$ \\
Accessibility to rehab centre & 30 & \\
Yes & $34.10 \%$ \\
\hline
\end{tabular}

Table 4 Utilization of rehabilitation centre

\begin{tabular}{lll}
\hline Variables & Frequency & Percentage \\
\hline Visit to rehabilitation center & 17 & \\
Yes & 69 & $19.30 \%$ \\
No & & $78.40 \%$ \\
Utilization rehab service & 17 & \\
Yes & 69 & $19.30 \%$ \\
No & & $78.40 \%$ \\
\hline
\end{tabular}

\section{Discussion}

The purpose of the study was to determine the level of disability, accessibility and utilization of rehabilitation services in gwan-gwan community. The research focus on type of disability, accessibility of rehabilitation service and utilization of the service by the people of the community.

In considering the 86 participants, irrespective of There function, awareness and health status, it was found that a higher percentage of the people are disabled. This is in line with WHO findings which estimates that over 650 million people live with disabilities worldwide or 1 in 10 of the world population. The study also focus on type of disability sustained by the participants and it was found that a greater percentage of the people have back deformoties. In contrast to this study, another study by Nalie Smith on disability survey in Kogi and Niger states of Nigeria it has been found that $37 \%$ had visual, $30 \%$ had mobility, $15 \%$ had hearing and $9 \%$ had mental or learning disabilities.

The study also focused on the knowledge, accessibility, visit and utilization of rehabilitation service. The result of the study had shown that $63.6 \%$ of the participants does not have access to rehabilitation centre. This could be due to the expensive nature of the services and the distance between the communities and the rehabilitation centers.

The Nigerians With Disability Decree of 1993 stipulated that: "disabled persons shall be provided in all public health institutions free medical and health services". This law is definitely for the archives and is not working. It is the duty of the members of our profession to make this part of our law work. The reasons for the accessibility issues need to be documented in a systematic way, from the perspectives of the people with disability and their care givers, professionals and organizations working to alleviate the conditions of people with disability. For example, the absence of practice standards along the continuum of care for stroke patients and the inability to provide adequate rehabilitation services through acute, sub-acute, rehabilitation units, and to the community, are major issues of poor accessibility of services. ${ }^{27}$

High level of disability (55.7\%) in the community is suggestive of poverty, it appears that majority of the participants are farmers and they use local tools for farming because they cannot afford modern tools. Poor people without disabilities can develop disability due to inadequate nutrition, unclean environments, disease, insufficient health services and poor infrastructure. ${ }^{27}$ The implication of very low accessibility, visit and utilization of rehabilitation services is that majority of the people are illiterate. Almost three quarter of those with disabilities are illiterate. ${ }^{28}$ Similarly, ${ }^{29}$ Observed that $80 \%$ of the study population had no contact with health services in black residential area of the Cape Peninsula.

In literature search it was observed that, various studies have observed different reasons for non utilization of rehabilitation services. ${ }^{29}$ Observed that the most common reasons cited for not using government speciality rehabilitative services were long hours in queue $(57 \%)$, ill-treatment by staff especially those relying on aids and appliances (45\%), and overall poor quality of care ${ }^{30}$ Observed better socio-economic status is closely associated with greater utilization of health care services among older persons. Patel SK states that treatment seeking behaviour of disabled persons depends not only on socio-economic factors but also on cultural factors, area of residence, literacy status, sex etc. Observed that the physical access to health service is a major hurdle for people with disabilities to reach and utilize these services. ${ }^{30}$

\section{Conclusion}

Most of the participants are disabled and majority of the participants do not have access to and therefore they do not utilize rehabilitation services.

\section{Recommendations}

Based on the findings of this research, the following recommendations were made:

i. There is need for the government of Nigeria to lead the way in making accessibility of rehabilitation centres a priority. This can be achieved by enacting laws which protect the accessibility rights of people living with disability.

ii. In a situation, where rehabilitation services are unable to reach the beneficiaries, strategies like community based rehabilitation (CBR) should be implemented with priority on literacy and good infrastructure.

iii. Improvement of literacy level, rehabilitation and health awareness, and good utilization among disabled.

iv. Campaign, seminars and community out-reach should be organise in the rural community to give them awareness about access, visit and utilization of rehabilitation service. 
v. Developing sustainable services and creating awareness regarding them, will lead to greater utilization of rehabilitation services and thus early diagnosis and disability limitation.

\section{Acknowledgements}

None.

\section{Conflict of interest}

The author declares no conflict of interest.

\section{References}

1. Abang TB. Disablement, disability and the Nigerian society. Disability Handicap \& Society. 1998;33(1):71-77.

2. Agrawal G, Keshri K. Disability and health care services among older people in india. 2009.

3. Ameh EA, Dogo PM, Nmadu PT. Emergency neonatal surgery in a developing country. Pediatr Surg Int. 2001;17(5-6):448-451.

4. Coghlan B. Trends in the global burden of disease. Primary health care course lecture, Centre for International Health, Burnet Institute; 2006.

5. Disler PB, Jacka E, Sayed AR, et al. The prevalence of loco motor disability and handicap in the cape peninsula. S Afr Med J. 2009;69:353355 .

6. Eide AH, Oderud T. Assistive technology in low income countries. In: Maclachlan M, Swartz L, editors. Disability and international development, Dordrecht, the Netherlands, Springer, 2009.

7. Elwan A. Poverty and Disability; A background paper for the world development report. World Bank; 1999.

8. Eleweke JC. A review of issues in deaf education under Nigeria's 6-3-3-4 education system. J Deaf Stud Deaf Educ. 2002;7(1):74-78

9. Gureje O, Lasebikan VO. Use of mental health services in a developing country. Results from the Nigerian survey of mental health and wellbeing. Social Psychiatry and Psychiatric Epidemiology. 2006;41(1):44 49.

10. Hamzat, TK. Dada OO. Accessibility of public buildings in Ibadan, Nigeria. Asia Pacific Disability Rehabilitation Journal. 2005;16(2):116.

11. Kiyaga NB, Moores DF. Deafness in sub-Saharan Africa. Am Ann Deaf. 2003;148(1):18-24.

12. Lang R, Upah L. Scoping study: Disability issues in Nigeria; 2008.

13. Laskar AR, Gupta VK, Kumar D. Psychosocial effect and economic burden on parents of children with locomotor disability. 2010;77(5):529533.

14. Lawn JE, Cousens S, Zupan J. 4 million neonatal deaths? When? Where? Why?. The Lancet. 365:891-900.
15. Lysack JT, Wyss UP, Packer TL, et al. Designing appropriate rehabilitation technology: a mobility device for women with ambulatory disabilities in India. International Journal of Rehabilitation Research. Internationale Zeitschrift fur Rehabilitation sforschung. Int $J$ Rehabil Res. 1999;22(1):1-9.

16. McColl MA, Boyce W. Disability advocacy organizations: a descriptive framework. Disability and Rehabilitation. 2003;25:380-392.

17. Mont D. Measuring Disability Prevalence. SP Discussion Paper No 0706. Washington DC, USA; 2007.

18. G MacLachan, Melling WN,Gcaza S. Realizing the rights of disabled people in Africa: an introduction to the special issue. Disability and Rehabilitation. 2009;31:1-6.

19. Olusanya BO, Ruben RJ. Reducing the burden of communication disorders in the developing world: An opportunity for the Millennium Development Project. JAMA. 2006;296(4):441-444.

20. Patel SK, Ladusingh L. Age pattern of onset of disability and treatment seeking behaviour of disabled persons in india; 2009.

21. Poulis I. The end of physiotherapy. Australian Journal of Physiotherapy.2007;53:71-72.

22. Qiu ZY. Rehabilitation need of people with disability in China: analysis and strategies [in Chinese]. Beijing, Huaxia Press; 2007.

23. Rahman A. Cluster randomized trial of a parent-based intervention to support early development of children in a lowincome country. Child: Care, Health and Development. 2009;35:56-62.

24. Scherer MJ. Assessing the benefits of using assistive technologies and other supports for thinking, remembering and learning. Disability and Rehabilitation. 2005;27(13):731-739.

25. Smith BJ, Bale JF, White KR. Sensorineural hearing loss in children. The Lancet. 2005;365:879-890.

26. Teasell R, Eng JJ. Evidence-based review of stroke rehabilitation. 11th ed. Viewed May 8, 2009.

27. UNPD. World Population Prospects: The 2004 Revision. New York: UN Population Division; 2005.

28. Wolfensohn JD. Poor disabled and shut out. Washington Post, 3 December. 2003

29. Yatch D, Hawkes C, Gould GL, et al. The global burden of chronic diseases: overcoming impediments to prevention and control. JAMA. 2004;291(21):2626-2622.

30. Zongjie $\mathrm{Y}$, Hong $\mathrm{D}$, Zhongxin $\mathrm{X}$, et al. A research study into the requirements of disabled residents for rehabilitation services in Beijing. Disability and Rehabilitation. 2007;29(10):825-833. 